\title{
Sponataneous perforation of Meckel's diverticulum presenting as peritonitis: a case report
}

\begin{abstract}
The incidence of Meckel's diverticulum (MD) varies between 1 and $2 \%$ and carries the lifetime risk of $4-6 \%$ to become symptomatic. The complications associated with MD include inflammation, hemorrhage, intussusception, volvulus, intestinal obstruction, and malignant transformation. However perforation of MD is a rare event and can mimick appendicular pathology. A 5 yr old male child presented to paediatric emergency with features of acute abdomen and successfully managed by ileal resection as well as perforated MD and reanastomosis. This case is being reported to highlight the rare presentation of perforated MD as peritonitis. Early diagnosis and timely operative intervention must occur in order to provide the best outcome for these patients.
\end{abstract}

Keywords: Meckel's diverticulum, perforation, peritonitis
Volume 10 Issue I - 2019

\author{
Vineet Mishra,' Yogender Singh Kadian, ${ }^{2}$ \\ Nikhil Tayal,' Arnav Kadian² \\ 'Department of General Surgery, Pt. BDS UHSR, India \\ ${ }^{2}$ Department of Paediatric Surgery, Pt. BDS UHSR, India
}

\begin{abstract}
Correspondence: Nikhil Tayal, Department of Genera Surgery, Pt. BDS UHSR, H. No. 214, Sector 4, Rohtak, Haryana, PIN-I2400I, India, Tel +9194161 I8268, Email nikhil.tayal555@gmail.com
\end{abstract}

Received: July 22, 2018 | Published: February 15, 2019

\section{Introduction}

German anatomist Johann Friedrich Meckel first described the embryological and pathological features in $1809 .{ }^{1}$ The incidence of Meckel's diverticulum (MD) varies between 1 and 2\% and carries the lifetime risk of 4-6\% to become symptomatic. ${ }^{2}$ Meckel's diverticulum is a commonest abnormality of gastrointestinal tract and it results from incomplete obliteration of patent vitellointestinal duct. It may be often found incidentally at the time of abdominal exploration. The complications associated with MD include inflammation, perforation, hemorrhage, intussusception, volvulus, intestinal obstruction, and malignant transformation. ${ }^{3}$ As in acute appendicitis, Meckel's diverticular obstruction results in distal inflammation, necrosis, or even perforation, leading to abscess or peritonitis. Other various pathologies leading to perforation are ulceration of ectopic gastric tissue, ingestion of foreign bodies, Littre's hernia, tumours such as leiomyosarcoma, lymphatic sarcoma, and poorly differentiated stromal tumour. ${ }^{2,4}$ The aim of this case report is to keep in mind the rare presentation of perforated MD as acute abdomen in paediatric age group.

\section{Case report}

A $5 \mathrm{yr}$ old male child presented to paediatric emergency with complaints of pain abdomen for 3 days, green colored vomiting and non passage of stool for 2 days and fever for 1 day. There was no history of similar complaints in the past. The patient was a full term vaginal delivery with immediate crying. He had no history of previous hospitalization, jaundice or any surgery. There was no history of breath holding spells. All the developmental milestones were at normal age. There was no history of altered bowel bladder habits. On examination, patient was having a pulse rate of $108 / \mathrm{min}$ and respiratory rate of $24 /$ min. On per abdomen examination, distension was present. On palpation, generalized tenderness and guarding was there and bowel sounds were absent.

His blood investigations showed $\mathrm{Hb}-10.5 \mathrm{gm} \%$, TLC $-9500 /$ $\mathrm{mm}^{3}$, DLC $-60 / 35 / 03 / 02$, platelet count $-2.5 \mathrm{lacs} / \mathrm{mm}^{3}$, blood urea $38 \mathrm{mg} / \mathrm{dL}$, random blood sugar $-64 \mathrm{mg} / \mathrm{dL}$, Serum sodium $-138 \mathrm{mEq} /$ $\mathrm{dL}$, serum potassium $-3.7 \mathrm{mEq} / \mathrm{dL}$. On erect $\mathrm{x}$-ray abdomen, there was multiple air fluid levels with no free air under diaphragm. On USG abdomen, there was evidence of free fluid with internal echoes in the pelvis, both paracolic gutter and inter bowel loops which was suggestive of perforation.

A diagnosis of peritonitis was made and decision was made to go for exploratory laparotomy. Operative findings were around $200 \mathrm{cc}$ of purulent fluid in peritoneal cavity with pus flakes over the small gut, liver and spleen. A diverticulum was present in the ileum, around 50 $\mathrm{cm}$ from ICJ at the antimesentric border, which was inflammed and burst at the tip. (Figure 1) (Figure 2). The segment of small bowel containing the diverticulum was resected and anastomosis of the two ends was done. Thorough peritoneal lavage was done. Patient was shifted to paediatric surgery ward after surgery and was kept nil per oral with active ryle's tube aspiration and intravenous fluids and antibiotics, and injection diclofenac for pain relief. Patient's vitals remained stable in the post operative period. Ryle's tube was taken out on $3^{\text {rd }}$ post operative day and was allowed sips of clear fluid. The oral intake was increased over 3 days as the patient tolerated the feeds. On the $6^{\text {th }}$ post operative day he was fully allowed orally and he was discharged under all satisfactory on the next day.

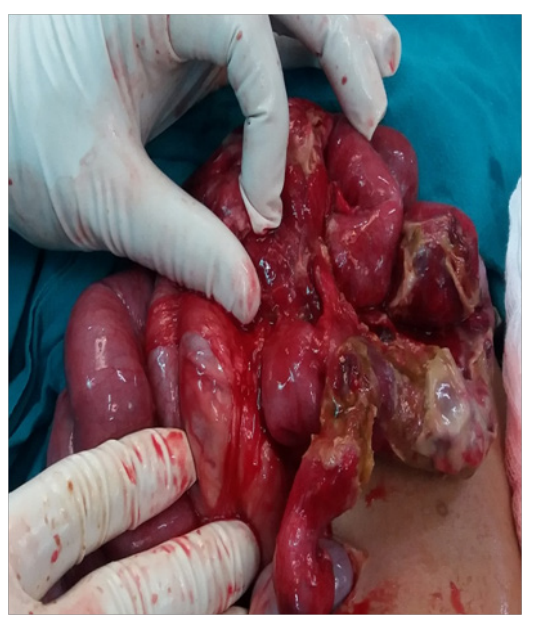

Figure I Perforated meckel's diverticulum. 


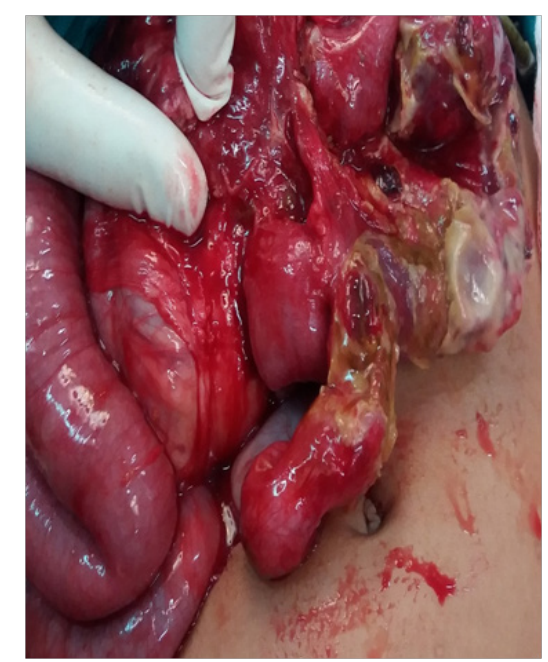

Figure 2 Perforated meckel's diverticulum.

\section{Discussion}

Meckel's diverticulum is the most frequent congenital anomaly of the gastrointestinal tract, resulting from the incomplete atrophy of the omphalomesenteric duct. Heterotopic tissues such as gastric, duodenal, colonic ones and rarely pancreatic mucosa can be found in the diverticula, as well as the anatomically normal intestinal mucosa. ${ }^{5}$ Perforation is noted to be an occasional consequence of acute Meckel's diverticulitis, but the exact rate of this has not been reported. The overall lifetime complication rate is approximately $4 \%$. The most common presentation associated with symptomatic Meckel's diverticulum is bleeding, followed by intestinal obstruction, diverticulitis, intussusceptions and neoplasm. However, perforation is very rarely seen and, in a review, was reported as being responsible for $0.5 \%$ of symptomatic diverticulum. ${ }^{2}$ The perforation of a Meckel's diverticulum may mimic acute appendicitis and present as an acute abdomen. The perforation of a Meckle's diverticulum is either caused by; foreign body due to irritation of foreign body and pressure necrosis of the diverticulum wall, or spontaneous perforation due to progressive inflammation of Meckle's diverticulum wall as our case, which produced peritonitis. ${ }^{6}$ A preoperative diagnosis of a complicated MD may be challenging because of the overlapping clinical and imaging features of other acute surgical and inflammatory conditions of the abdomen. A more specific diagnosis, however, will lead to greater recourse to a laparoscopic approach in its treatment. ${ }^{6,7}$

\section{Conclusion}

In patients with clinical signs of acute abdomen, Meckel's diverticulum and its potential complications should be kept in mind. Meckel's diverticulum complications are uncommon and challenge to diagnose. Early diagnosis and timely operative intervention must occur in order to provide the best outcome for these patients. Spontaneous perforated MD often presents as acute abdomen and its preoperative diagnosis is difficult.

\section{Acknowledgments}

None.

\section{Conflicts of interest}

Author declares no conflicts of interest.

\section{References}

1. Yorganci K, Ozdemir A, Hamaloglu E, et al. Perforation of acute calculous Meckel's diverticulitis: a rare cause of acute abdomen in elderly. Acta Chir Belg. 2000;100(5):226-227.

2. Modi S, Pilai SK, DeClercq S. Perforated meckel's diverticulum in an adult due to fecolith: A rare case report and review of literature. Int J Surg Case Rep. 2015;15:143-145.

3. Ding Y, Zhou Y, Ji Zh, et al. Laparoscopic Management of Perforated Meckel's Diverticulum in Adults. Int J Med Sci. 2012;9(3):243-247.

4. Hager M, Maier H, Eberwein M, et al. Perforated Meckel's diverticulum presenting as a gastrointestinal stromal tumor: a case report. J Gastrointest. Surg. 2005;9(6):809-811.

5. Tas I, Culcu S, Duzkoylu Y, et al. A rare cause of acute abdomen: Perforation of double Meckel's diverticulum. Case Reports in Gastrointestinal Medicine. 2015:648417.

6. Farah RH, Avala P1, Khaiz D, et al. Spontaneous Perforation of Meckel's Diverticulum: A case report and review of literature. Pan Afr Med J. 2015;20:319.

7. Quarrie R, Lindsey D, Bahner DP. Review of the Incidence and Management of Meckel's Diverticulum. Austin J Surg. 2014;1(3):1015. 